existence has totalled about 35 million dollars. Of the 532 research projects undertaken in 1955,132 were for government agencies ; but in terms of dollars the ratio of commercial projects to government projects was $56 \cdot 6: 43 \cdot 4$. Following a final decision as to the site, rapid progress was made in developing building programmes for offices and research activities. The Associate Plan was further extended, and by the end of the year 116 firms or individuals had pledged or contributed one or more units of 15,000 dollars, totalling 2,266,525 dollars, to this fund for improving the Institute's research facilities.

Progress was made in the solar energy programme, including a study by the Institute of flat-plate collectors, in which a solar-heat pump from the Somor Company of Italy was used, studies of the feasibility and design of extremely large solar furnaces for high-temperature research, and the production of a directory and bibliography of research in this field. A reflector-type furnace for temperatures in the range $2,000^{\circ}-3,000^{\circ} \mathrm{C}$. has been designed which can be used interchangeably with three sources of radiation-solar, flame and the electric arc. A feature of the activities during the year in this field was the international symposium on applied solar energy, held in Arizona during November 1-5. A new phase of activity in the field of nuclear energy was to assist companies contemplating entering this field by evaluating possible markets and analysing the need for development work and associated manufacturing, marketing and financial problems. A Nuclear Energy Service was established to provide a source of up-to-date information on developments, and a study of the most suitable design of industrial reactor led to the selection of a reactor of the heterogeneous type, moderated by heavy water, with a 10-MW. hoat output and a maximum neutron flux density of $2 \times 10^{14}$ neutrons sq. cm./sec. Its powerlevel is at least ten times that of most research reactors, and it is proposed that the co-operative reactor laboratory should be owned by a non-profit corporation, subsidiary to the Institute, and that the reactor would also be available for use on a contract basis for applied research. Nuclear engineering studies included radiation studies of food products and of chemical reactions induced by radiation, while the possibilities of radiation as an industrial tool were being explored.

An extensive study was made of the research needs of the forest industries, particularly of the West, and in a new physical sciences laboratory reactions of hydrocarbons and their derivatives were being studied at pressures up to $10,000 \mathrm{lb}$./sq. in. in a new type of reaction chamber providing complete operating safety at low test. A new wing in the chemical engineering laboratory contains high-temperature clectric furnaces, a spray dryer, a high-pressure air system and kindred equipment for the development of hightemperature alloys and other materials. The enlarged laboratory is also being used for trials of new processes on a scalo sufficient to provide information for the design of pilot plant. In a classified study of ballistic and physical properties of solid propellants, special equipment has been provided for measuring the rate of burning of propellants in strand form, ignition time, and tensile strength at high rates of strain application. The television and vacuum-tube laboratory has been approximately doubled in capacity and has been concerned with research on video recording, the more efficient utilization of television channels and industrial applications of television techniques. From a siudy of existing air-modulated loudspeakers and of the principles and factors affecting efficiency, the Institute has been able to design a prototype loudspeaker-the Stanford airstream modulator-costing about a fifth as much to build as other units of this type, with about 80 per cent of the theoretical efficiency and which, with only 10 watts of air energy and 10 watts of air control, can be heard about 1.5 miles away. The addition of a now electronic computer greatly increased the ability of the Computation Centre to handle large problems, and in a single afternoon an operations research team obtained data on a complex study of the most economic method of dispatching empty freight cars that normally would have taken one man two years to procure. New equipment has also been installed in the controlsystems laboratory for studies of surface physics and materials, and a new laboratory established for research on special problems in the graphic arts. The Poulter laboratories have made contributions to the understanding of detonation and hydrodynamics of shock-pulse phenomena, with consequent severalfold improvement in the efficiency of military and civil explosives, and are also engaged in combustion and genoral high-pressure research. An irradiation study initiated by the Sequoia Process Corporation led to a new type of polyethylene resist. ant to $150^{\circ} \mathrm{C}$. and suitable for high-temperature application in aircraft and electronics ; and, with the Bank of America, the Institute has designed an electronic recording machine which automatically does all checking of customers' accounts.

\section{FUTURE NUMBERS OF UNIVERSITY STUDENTS IN BRITAIN}

$A^{N}$ $\mathrm{N}$ address on the number of university students, which Lord Simon of Wythenshawe delivered to the Court of the University of Manchester on Novembor 16, was afterwards published in a revised and extended form in the February issue of the Universities Quarterly, and a reprint of this article has been issued entitled "Future Numbers of University Students : the Desperate Need for Technologists"*. In his original address, Lord Simon discussed separately both the national problem and the particular contribution Manchester could be expected to make alike in respect of the general need for expansion and the shortage of technologists; he expressed the view that no expansion should be contemplated at Manchester beyond the five thousand students for which the now buildings would provide, oxcept that, in addition, the College of 'Technology should expand to reach a student population of fifteen hundred within a decade. In the pamphlet now issued, Lord Simon looks at the question of student numbers purely from a national point of view and, after revicwing the expansion since 1911, considers more particularly the measures which should be taken to meet the situation likely to arise in the next ten years. Ho assumes that university standards will not be raised, that the universities will continue to accept approximately the present proportion of sixth-form pupils and that accordingly they will expand to the extent necessary to admit * Future Numbers of University Students : the Desperate Need for Technologists. (Reprinted from Universities Quarterly, February 1956.) By Lord Simon of Wythenshawe. Pp. 15. (London: Turnstile Press, 
the increased number of those attaining present standards which will be forthcoming when the increased population passing through the schools reaches the university stage from 1962 onwards. He estimates that entrants in 1965 are likely on these assumptions to be 40-100 per cent above the present level, and that it is imperative to begin at once to erect the necessary buildings.

Lord Simon lays his main stress on technology. Pointing out that the number of degrees and diplomas in technology awarded by the universities in Great Britain has been decreasing since 1950 (from 3,593 to 3,359 ), he emphasizes that both the U.S.S.R. and the United States are already producing each year about twice as many graduates in science and technology per thousand of population as Great Britain, and that in the U.S.S.R. the output during the past five years has increased by more than 10 per cent a year. The Federal Institute of Technology at Zurich, he points out, has at present 2,700 full-time degree students, which is more than the three largest technological institutions in Britain put together, and the totals of 3,600 and 3,400 graduate engineers produced in Britain in 1950 and 1954, respectively, compare with 50,000 and 20,000, respectively, in the United States and 28,000 and 54,000 in the U.S.S.R. $\mathrm{He}$ urges that the rate of building for universities should be increased at once to provide reasonable accommodation for a 50 per cent increase in the number of students by 1965, and immediate and energetic action should also be taken to increase the output of graduates in technology by 10 per cent a year, with an ultimate output of at least ten thousand engineers a year. As a contribution to this end, he suggests the appointment of a small Royal Commission to report on the situation within six months.

\section{MATING SYSTEMS OF FUNGI}

$\mathrm{T}$ a paper under this title, J. H. Burnett (New Phytol., 55, 1, 50; 1956) has attempted to classify the principal kinds of mating systems, to devise an appropriate terminology for them, and to describe how they operate and are controlled. He points out that, so far, there is no adequate and agreed terminology for describing fungal mating systems.

The terminology now proposed includes the fol. lowing. Under the term 'heteromixis', he would include those instances, or imply the condition, where sexual reproduction only results from the fusion of genetically different nuclei normally derived from different thalli. Heteromixis includes: (1) 'dimixis', the condition where there are two, and only two, types of complementary nuclei which control mating, the nuclear types being determined by two allelomorphs at a single' locus; (2) 'diaphoromixis', the condition where several types of complementary nuclei occur which control mating, the nuclear types being determined by multiple allelomorphs at one or two loci, the bipolar and tetrapolar conditions, respectively; and (3) 'homoheteromixis', this being an essentially heteromictic condition where sexual reproduction results only from the fusion of genetically different nuclei derived normally from the same thallus; such forms are derived from dimictic or diaphoromictic forms, hence the derived terms, 'homo-dimictic' and 'homo. diaphoromictic'.
'Homomixis' is defined as the condition where sexual reproduction can result from the fusion of genetically similar nuclei, these being usually derived from the same thallus. 'Amixis' is defined as the condition where the essential events of sexual reproduction are lacking but where the pre-conjugation and post-meiotic events normally associated with sexual reproduction may occur. The author prefers this term to 'apomixis' since the condition described is one in haploid organisms. It is so defined as to cover a wider range of conditions than does apomixis as used for conditions in higher plants. The author describes how the principal mating systems operate, and concludes that the factors which control compatibility are pleiotropic in their effects. This sug. gests that mating-type factors are, in fact, groups of closely linked genes.

From a review of the evolution of mating systems, he concludes that it is not possible at present to give a general account of this phenomenon. It is, however, possible to make suggestions concerning the origin and evolutionary processes involved in some of the systems, and some hypotheses are developed. A general conclusion is that mating systems have arisen in a variety of ways and that, in the first instance, selection of potential mating-type factors may not have been for their effects upon compatibility.

\section{RESEARCHES IN THE ARCTIC OCEAN}

$T$ HE aretic, up to the North Pole, might be an open sea for part of each year if it were not for the piling up of pack ice into thick ridges by storms. Otherwise, ice formed during the intensely cold winter nights would be thawed completely by September. This speculation is advanced by Prof. G. E. MacGinitie, of the California Institute of Technology, in a technical report on arctic life just published by the Smithsonian Institution. Prof. MacGinitie was principal investigator at the Navy's Arctic Research Laboratory at Point Barrow, Alaska. It is highly improbable that the sea surface as a whole ever freezes during the winter to a depth of much over $6 \mathrm{ft}$. Thousands of lakes and ponds in the country behind the arctic coasts freeze to depths of more than $7 \mathrm{ft}$., yet this ice melts entirely during the summer.

During the storms of gale force that sweep over the arctic basin, the surface ice is piled up into windrows which may be several times $6 \mathrm{ft}$. thick. These drift together and constitute the great arctic pack. Summer melting is more than compensated for by the increased thickness of windrowed ice. Ice over offshore areas which has not been piled up by wind and wave disappears completely by September. The movement of the ice pack itself may have some influence on animal distribution. This pack constitutes about 70 per cent of the arctic ice. It is never stable. Previous investigations have shown that it may move as much as 1,000 miles in nine months. There is good evidence, Prof. MacGinitie says, for considering the pack as a great, moving field, the general direction of which is from north-east Siberia to the east of Greenland.

Prof. MacGinitie has also made some observations about Eskimo life. 